\title{
Veverimer: an advance in base therapy for metabolic acidosis
}

\author{
Clayton Brady ${ }^{1}$, Elie R. Chemaly ${ }^{2}$, James W. Lohr ${ }^{2}$, Mark D. Parker ${ }^{1}$ \\ ${ }^{1}$ Department of Physiology and Biophysics, ${ }^{2}$ Department of Medicine, Division of Nephrology, Jacobs School of Medicine and Biomedical Sciences, \\ The State University of New York: University at Buffalo, Buffalo, NY, USA \\ Correspondence to: Mark D. Parker. Department of Physiology and Biophysics, Jacobs School of Medicine and Biomedical Sciences, The State \\ University of New York: University at Buffalo, 955 Main Street, Buffalo, NY 14203, USA. Email: parker28@buffalo.edu. \\ Comment on: Wesson DE, Mathur V, Tangri N, et al. Long-term safety and efficacy of veverimer in patients with metabolic acidosis in chronic kidney \\ disease: a multicentre, randomised, blinded, placebo-controlled, 40-week extension. Lancet 2019;394:396-406.
}

Submitted Mar 24, 2020. Accepted for publication Apr 22, 2020.

doi: $10.21037 / \mathrm{atm}-20-2827$

View this article at: http://dx.doi.org/10.21037/atm-20-2827

\section{Introduction}

Metabolic acidosis (MAc) is defined as a reduction in plasma bicarbonate concentration $\left\{\left[\mathrm{HCO}_{3}^{-}\right]<22 \mathrm{mEq} / \mathrm{L}\right\}$ that is not a compensatory response to respiratory alkalosis (1). MAc is one of the earliest complications of chronic kidney disease (CKD), and increases in prevalence with declining glomerular filtration rate (1). Overall, MAc occurs in $15 \%$ of all CKD patients, and in up to $37 \%$ of patients with stage 4 CKD (2). The treatment of MAc in CKD (CKD$\mathrm{MAc}$ ) can be challenging because of the need to introduce $\mathrm{HCO}_{3}^{-}$without surplus counterions, such as sodium $\left(\mathrm{Na}^{+}\right)$, which can exacerbate fluid overloaded states, or potassium $12\left(\mathrm{~K}^{+}\right)$, which can precipitate hyperkalemia (1). Moreover, the 3 introduction of excess alkali can itself be harmful (1).
To avoid the unwanted effects associated with alkali been developed. Veverimer is an acid-binding polymer that raises plasma $\left[\mathrm{HCO}_{3}^{-}\right]$without introducing unwanted cations. In the June 2019 edition of Lancet, Wesson et al. presented the results of a randomized placebo-controlled trial that examined the safety and efficacy of veverimer in the treatment of CKD-MAc (3). In this commentary, we review those findings in the context of the underlying basic science and prevailing treatment strategies.

\section{$\mathrm{HCO}_{3}{ }^{-}$and the kidneys}

The $\mathrm{HCO}_{3}^{-}$buffering-system is essential for maintaining plasma $\mathrm{pH}$ within normal range $(\mathrm{pH} 7.35-7.45)$ in the face of the daily load of dietary and endogenously-produced acids. therapy, the first-in-class pharmaceutical, veverimer, has

$$
\mathrm{HCO}_{3}^{-}+\mathrm{H}^{+} \rightleftharpoons \mathrm{CO}_{2}+\mathrm{H}_{2} \mathrm{O}
$$

The consumption of $\mathrm{HCO}_{3}{ }^{-}$by the daily acid-load 31 requires the generation of equimolar amounts of $\mathrm{HCO}_{3}^{-}$in 32 order to maintain an adequate $\mathrm{HCO}_{3}{ }^{-}$pool [normal plasma 33 $\left.\left(\mathrm{HCO}_{3}{ }^{-}\right)=23-30 \mathrm{mEq} / \mathrm{L}\right]$ (1) to preserve the plasma's $\mathrm{pH} 34$ and buffer capacity. $\mathrm{HCO}_{3}^{-}$replenishment is predominantly 35 accomplished by epithelial cells in the proximal tubules of the 36 kidneys by a series of metabolic reactions that result in the 37 production of $\mathrm{H}^{+}$or $\mathrm{NH}_{4}^{+}$(which are excreted in the urine) 38 and $\mathrm{HCO}_{3}^{-}$[which is absorbed into circulation: reviewed in (4)]. 39 Failure of the kidneys to match the daily acid-load with an 40 equivalent amount of $\mathrm{HCO}_{3}^{-}$production results in MAc. The pathogenesis of CKD-MAc is a decrease in renal function, which impairs the renal production of $\mathrm{HCO}_{3}^{-}$(1). CKD-MAc has been implicated in the development of osteopenia and osteoporosis, decreased muscle mass, decreased insulin release and sensitivity, vascular endothelial dysfunction, progression of CKD to end-stage renal disease (ESRD), cardiovascular disease, and an overall increased risk of death [Figure 1 and see reference (5)]. Thus, the continued evaluation of $\mathrm{HCO}_{3}^{-}$ status in CKD patients is essential and findings of CKD-MAc should prompt initiation of treatment. However, therapy is often limited or even impossible due to insufficient treatment options and the prevalence of comorbidities, underscoring the need for the development of new therapies for CKD-MAc.

\section{Prevailing alkali therapies}

Dietary management is often a first-line treatment to

\section{5} 36 37 


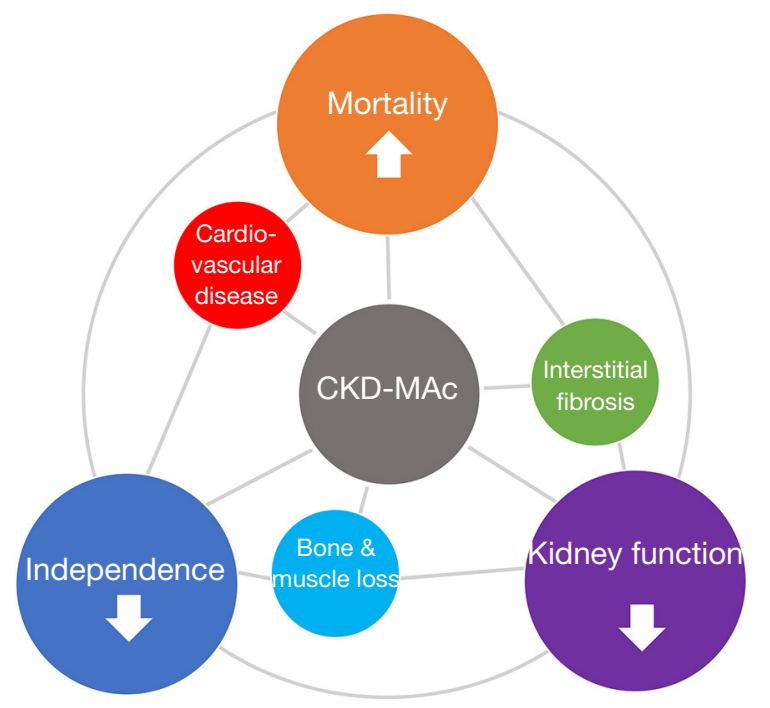

Figure 1 A network of pathologies associated with CKD-MAc. The effects of CKD-MAc are multifaceted and incompletely understood. Acid retention can trigger inflammatory mechanisms (e.g., complement activation and cytokine release), which leads to kidney interstitial fibrosis and worsening of CKD. Chronic low $\mathrm{pH}$ decreases bone mineralization and increases muscle protein metabolism leading to increased fragility in patients. Activation of hormonal mechanisms (e.g., endothelin and angiotensin II release) can also damage the kidney, as well as cause fluid retention and atherosclerotic plaque development that can lead to development of cardiovascular disease. Evidence that high $\left(\mathrm{HCO}_{3}^{-}\right)$may also be associated with cardiovascular disease adds to the complexity of potential treatment guidelines. Overall, worsening CKD to the point of needing dialysis and the progression of co-morbid conditions such as fragility and cardiovascular disease, together decrease independence and contribute directly to mortality. See reference (5) for a more thorough review.

restore plasma $\mathrm{pH}$, with patients instructed to eat more fruits and vegetables (which contain a greater proportion of base-producing amino acids) and decrease their intake of animal protein (which contains a greater proportion of acid-producing amino acids) (1). However, many fruits and vegetables are also rich in $\mathrm{K}^{+}$and therefore such diets require careful management in $\mathrm{CKD}$ patients due to the increased risk of hyperkalemia (1). The current standard treatment recommendation for CKD-MAc, as defined in the Kidney Disease Improving Global Outcomes guidelines, is to begin oral $\mathrm{NaHCO}_{3}$ (baking soda) administration in any patient with serum $\left[\mathrm{HCO}_{3}^{-}\right]<22 \mathrm{mEq} / \mathrm{L}$ (6). Orally-dosed $\mathrm{HCO}_{3}{ }^{-}$neutralizes gastric acid to stimulate hydrochloric acid (HCl) secretion by parietal cells and enhance delivery of $\mathrm{HCO}_{3}{ }^{-}$into the blood (Figure 2), mimicking a postprandial alkaline tide. The grade given to this recommendation is $2 \mathrm{~B}$; with the implication that the quality of evidence for the recommendation is "moderate" and that "different choices will be appropriate for different patients" (6). However, the use of $\mathrm{NaHCO}_{3}$ therapy is off label for the chronic treatment of MAc in the USA (3). As mentioned, a major complication of oral $\mathrm{HCO}_{3}{ }^{-}$administration is that it necessarily includes a counterion $\left(\mathrm{Na}^{+}\right.$or $\left.\mathrm{K}^{+}\right)$, which may require dietary management to avoid $\mathrm{Na}^{+}$-related fluid retention or hyperkalemia (8). Another complication is that the reaction between $\mathrm{HCO}_{3}{ }^{-}$and $\mathrm{HCl}$ generates $\mathrm{CO}_{2}$, which can cause bloating and stomach discomfort, often limiting patient compliance (8). While exceedingly rare, in severe cases the pressure caused by $\mathrm{CO}_{2}$ build-up can result in gastric rupture (9). However, both vegetarian diets and oral $\mathrm{HCO}_{3}^{-}$dosing are appealing in their simplicity and availability and can be feasible options, given appropriate dietary counseling $(10,11)$. A third form of treatment is citrate-based therapy (oral dosing of $\mathrm{Na}^{+}$- or $\mathrm{K}^{+}$-citrate), which increases plasma $\mathrm{HCO}_{3}{ }^{-}$through conversion of citrate to $\mathrm{HCO}_{3}^{-}$in the liver and, in general, has a milder gastrointestinal side-effect profile than $\mathrm{HCO}_{3}^{-}$-based therapy (1). A caution to investigations implementing any form of alkaline therapy is that too much $\mathrm{HCO}_{3}{ }^{-}$can also be harmful (1). For example, the association between $\left[\mathrm{HCO}_{3}^{-}\right]$and cardiovascular disease, which accounts for the majority of deaths in the CKD population (12), 

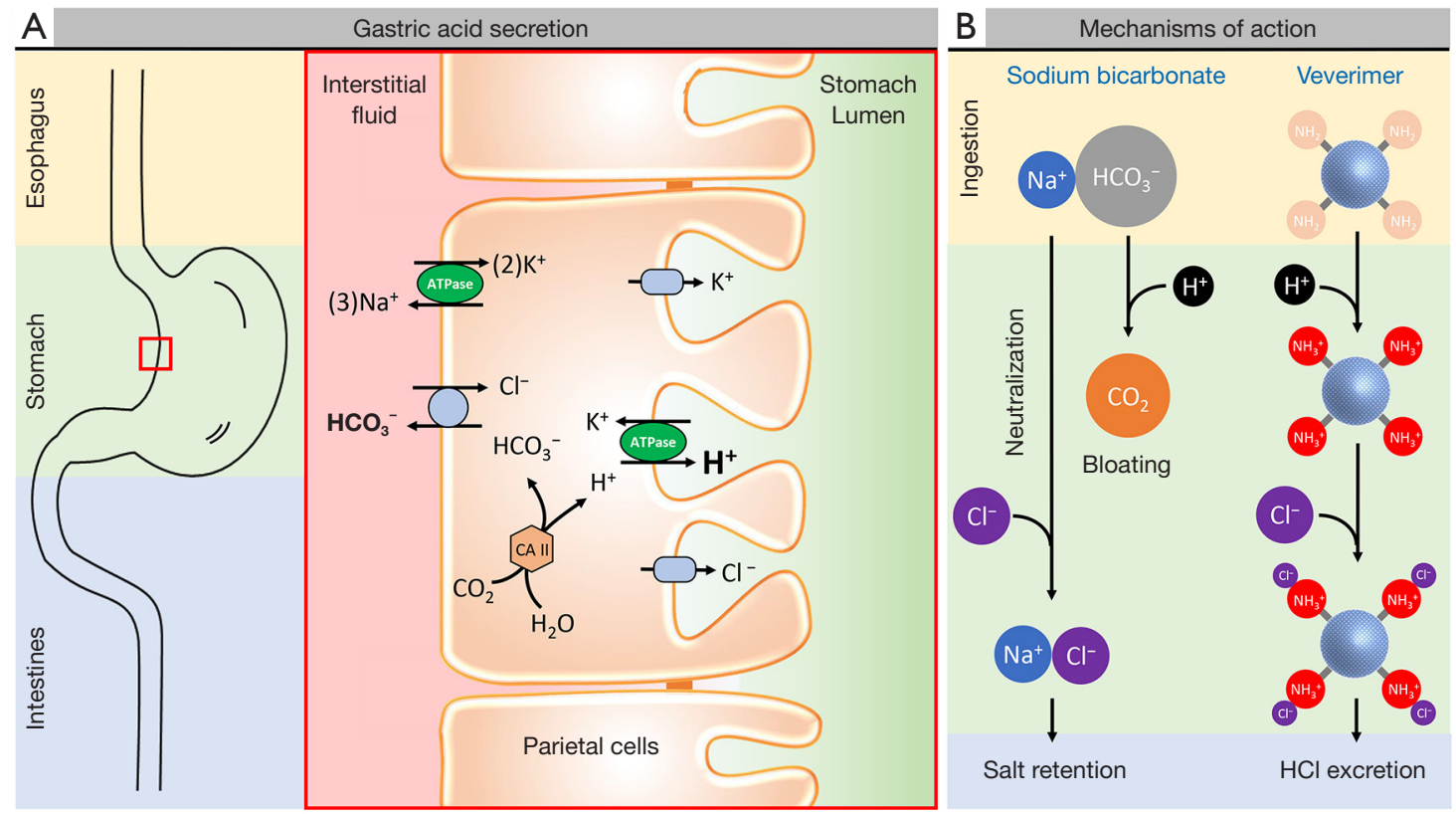

Figure 2 The mechanism of action of veverimer versus sodium bicarbonate in the treatment of MAc. (A) Parietal cells secrete $\mathrm{H}^{+}$across their apical membranes using a $\mathrm{H}^{+} / \mathrm{K}^{+}$-ATPase. Intracellular $\mathrm{H}^{+}$are replaced by the action of carbonic anhydrase II (CAII), which also generates $\mathrm{HCO}_{3}{ }^{-}$that must be absorbed into the blood to maintain parietal cell $\mathrm{pH}$. This is achieved by the exchange of intracellular $\mathrm{HCO}_{3}{ }^{-}$for interstitial $\mathrm{Cl}^{-}$, a process mediated by the anion exchange protein AE2. (B) $\mathrm{HCl}$ in the stomach lumen may be neutralized by orally administered $\mathrm{NaHCO}_{3}$ with the production of unwanted $\mathrm{NaCl}$ and $\mathrm{CO}_{2}$. Veverimer sequesters $\mathrm{HCl}$ in the stomach lumen, removing $\mathrm{H}^{+}$without generating these byproducts. The effectiveness of veverimer is such that it temporarily causes gastric $\mathrm{pH}$ to rise between 1.5-3.0 units (7). The replacement of gastric acid that was neutralized by these treatments results in the enhanced production of $\mathrm{HCO}_{3}{ }^{-}$by parietal cells, mimicking a postprandial alkaline tide.

is 'U-shaped'; too much $\mathrm{HCO}_{3}{ }^{-}$can be as detrimental as too little $(13,14)$.

\section{The action and efficacy of veverimer}

Veverimer (also known as TRC101) is an orallyadministered, non-absorbed, binder of $\mathrm{HCl}$ that takes the form of $\sim 100 \mu \mathrm{m}$ diameter beads composed of crosslinked, high-molecular-weight polyamines (15). Veverimer acts by sequestering $\mathrm{HCl}$ from the stomach which, like the action of orally-dosed $\mathrm{NaHCO}_{3}$, stimulates gastric $\mathrm{HCl}$ secretion and enhances delivery of $\mathrm{HCO}_{3}{ }^{-}$into the blood (Figure 2). The HCl-bound veverimer is ultimately excreted in the feces. Importantly, unlike orally dosed $\mathrm{NaHCO}_{3}$, veverimer does not introduce unwanted absorbable cations into the gastrointestinal tract, nor does its action generate $\mathrm{CO}_{2}(7)$.

A side-by-side comparison of veverimer and $\mathrm{NaHCO}_{3}$ has yet to be performed but, in Lancet article that is the subject of this commentary, Wesson et al. report the results of a randomized, phase- 3 clinical trial that examined the safety and efficacy of veverimer versus a placebo in the treatment of CKD-MAc over a 52-week period (3). This was a 40-week extension of a 12 -week parent study (16). Of the 196 CKD patients enrolled in this extension, 114 received veverimer orally and 82 received an oral placebo (microcrystalline cellulose, a common bulking-agent in tablets that has no known or anticipated effects on acidbase balance). The study's primary endpoint was safety (incidence and severity of adverse events), with secondary endpoints related to the efficacy of veverimer, such as blood $\left[\mathrm{HCO}_{3}^{-}\right]$and physical functioning. Over the original 12-week parent study some patients were kept on a stable dose of oral alkali therapy as part of their 'baseline'; this therapy was kept constant and no other $\left[\mathrm{HCO}_{3}^{-}\right]$raising therapies were allowed to be initiated. Before entering the 40 -week extension, patients with $\left[\mathrm{HCO}_{3}{ }^{-}\right] \geq 22 \mathrm{mEq} / \mathrm{L}$ were taken off any prior oral alkali therapy, however if their $\left[\mathrm{HCO}_{3}{ }^{-}\right]$then fell $<22 \mathrm{mEq} / \mathrm{L}$, and could not be corrected 
with maximal dosing of the study drug, oral alkali therapy was reinstated at the patient's week-12 dosage. There were no specific dietary restrictions, however all patients received dietary counseling.

In this cohort of patients, with moderate to severe CKD and baseline $\mathrm{HCO}_{3}{ }^{-}$concentrations of $14-20 \mathrm{mEq} / \mathrm{L}$, veverimer performed well compared to placebo both in terms of efficacy and safety. In regard to efficacy, more patients on veverimer than placebo had an increase in blood $\left[\mathrm{HCO}_{3}{ }^{-}\right]$by at least $4 \mathrm{mEq} / \mathrm{L}$ above baseline or to within target range $(22-29 \mathrm{mEq} / \mathrm{L})$ at week 52 , with subgroup analysis suggesting that these effects are most pronounced in individuals over 65 years or in females. The mean blood $\left[\mathrm{HCO}_{3}{ }^{-}\right]$of the veverimer treated group was higher than placebo at all timepoints starting at week 1 , was maximized by 4 weeks of treatment, and was sustained over the trial period. Furthermore, patients taking veverimer reported increased physical functioning over the 52 weeks, a finding supported by improvements in physical-testing metrics such as 'time from chair to standing'. In regard to safety, the authors report that veverimer was well tolerated with no significant difference from placebo in occurrence of adverse effects. Gastrointestinal events were the most commonly reported adverse effects in both groups, but were mild or moderate and none required treatment or resulted in discontinuation from the study.

\section{Can veverimer delay the progression of CKD?}

Whether treatment of CKD-MAc with veverimer slows the progression of CKD is a major unanswered question. The study by Wesson et al. was not powered to assess the effect of veverimer on CKD progression (the sample size of the 40 -week extension was bounded by the number of eligible patients who followed through from the parent study); the primary endpoint of the extension was safety. However, in consideration of the entire 52-week study (including those 21 individuals who discontinued during the parent trial or who did not continue into the extension phase), the authors do report a statistically significant improvement in their composite endpoint (number of deaths, need for renal replacement therapy, or a decline in the estimated glomerular filtration rate, eGFR, of $>50 \%$ ) in the veverimer-treated group (4\%) compared to placebo $(12 \%)$.

This improvement in the composite endpoint in the veverimer-treated group is similar to that achieved by oral $\mathrm{NaHCO}_{3}$ dosing in the 'Use of $\mathrm{HCO}_{3}{ }^{-}$in Renal
Insufficiency' (UBI) study, which was published just two months later (11). The UBI study was an open-label, controlled trial, investigating the effect of $\mathrm{NaHCO}_{3}-$ administration on the preservation of kidney function, with secondary endpoints of time to renal replacement therapy and all-cause mortality. The study enrolled 740 total patients, making it the largest to date examining $\mathrm{NaHCO}_{3}$ administration in CKD. Using a similar target $\left[\mathrm{HCO}_{3}^{-}\right]$ range and achieving a similar efficacy in reaching that target compared to the veverimer trial, the UBI study reports a significant reduction in risk of their composite endpoint (death, need for dialysis, or doubling of creatinine). This might be taken as a promising indicator for an ongoing trial that is specifically designed to investigate the effect of veverimer versus placebo on CKD progression (ClinicalTrials.gov, Identifier: NCT03710291), which is due for completion in 2022.

A significant advantage of the veverimer study is the widening of inclusion criteria for hypertension and heartfailure to systolic blood pressure $<170 \mathrm{mmHg}$ and New York Heart Association (NYHA) Functional Classification IIII heart failure (including individuals with slight or marked limitation of physical activity), respectively. These patients are often sensitive to $\mathrm{Na}^{+}$, and thus had been excluded in previous studies examining effects $\mathrm{Na}^{+}$-based alkali therapies (17-19). For example, the UBI study (11) only included patients with systolic blood pressure $<150 \mathrm{mmHg}$ and NYHA Functional Classification I-II heart failure (excluding individuals with marked limitation of physical activity), similar to the earlier smaller studies examining $\mathrm{NaHCO}_{3}$ administration (17-19). Thus, as Wesson et al. point out, the veverimer trial was able to recruit a cohort that was probably a more accurate representation of the general CKD population (3).

On the other hand, no past or present veverimer trial allows the direct comparison of the efficacy of veverimer to that of traditional therapies such as $\mathrm{NaHCO}_{3}$ in delaying the progression of CKD or improving other clinical outcomes. Considering the simplicity and benefit of $\mathrm{NaHCO}_{3}$ supplementation demonstrated recently in the UBI study, in conjunction with the benefit of veverimer demonstrated by Wesson et al., a rigorous head-to-head comparison between $\mathrm{NaHCO}_{3}$ and veverimer would provide optimal guidance to the clinician. The ideal study would include an epidemiologically diverse patient population and would be powered to assess the long-term safety and efficacy of veverimer and $\mathrm{NaHCO}_{3}$ compared to placebo in delaying the progression of CKD towards end-stage renal disease. 
Future studies would also address the benefit of alkaline therapy in a broader range of renal dysfunction, in contrast to the study by Wesson et al. which included patients with eGFR ranging between 20 and $40 \mathrm{~mL} / \mathrm{min}$ with relatively moderate albuminuria (3).

However, the treatments need not be mutually exclusive; indeed some veverimer trial subjects were allowed to continue alkali therapy if a maximum dose of veverimer was not effective at normalizing $\left[\mathrm{HCO}_{3}^{-}\right]$. One might envision a situation in which traditional alkali therapies could be maintained as a simple intervention in early stages of CKD in individuals who tolerate it well, whereas veverimer may be most valuable later in disease progression when the additional load of $\mathrm{Na}^{+}$or $\mathrm{K}^{+}$is contraindicated. Patients may qualify for combination therapy in advanced disease: concerns of fluid overload could be mitigated by the use of diuretics.

\section{Beyond CKD-MAC}

For healthy older adults, a study investigating the association between $\left[\mathrm{HCO}_{3}^{-}\right]$and mortality, demonstrated a $22 \%$ higher risk of death in patients with $\left[\mathrm{HCO}_{3}^{-}\right]$ $<23 \mathrm{mEq} / \mathrm{L}$ (20). Importantly, this risk was independent of $\mathrm{pH}$ \{i.e., low $\left[\mathrm{HCO}_{3}^{-}\right]$could be due to MAc or respiratory alkalosis\}, suggesting that $\left[\mathrm{HCO}_{3}^{-}\right]$itself is a vital parameter independent of its consequence for $\mathrm{pH}$. Thus, there are conditions besides CKD-MAc in which drugs such as veverimer could be valuable to raise $\left[\mathrm{HCO}_{3}^{-}\right]$. It will be interesting to learn from future studies how the efficacy of veverimer compares to that of traditional alkali therapies in ameliorating the detrimental effects of low $\left[\mathrm{HCO}_{3}{ }^{-}\right]$.

\section{Acknowledgments}

Funding: None.

\section{Footnote}

Provenance and Peer Review: This article was commissioned and reviewed by the Section Editor Dr. Cheng Yuan (Zhongnan Hospital, Wuhan University, China).

Conflicts of Interest: All authors have completed the ICMJE uniform disclosure form (available at http://dx.doi. org/10.21037/atm-20-2827). The authors have no conflicts of interest to declare.

Ethical Statement: The authors are accountable for all aspects of the work in ensuring that questions related to the accuracy or integrity of any part of the work are appropriately investigated and resolved.

Open Access Statement: This is an Open Access article distributed in accordance with the Creative Commons Attribution-NonCommercial-NoDerivs 4.0 International License (CC BY-NC-ND 4.0), which permits the noncommercial replication and distribution of the article with the strict proviso that no changes or edits are made and the original work is properly cited (including links to both the formal publication through the relevant DOI and the license). See: https://creativecommons.org/licenses/by-nc-nd/4.0/.

\section{References}

1. Raphael KL. Metabolic acidosis in CKD: Core Curriculum 2019. Am J Kidney Dis 2019;74:263-75.

2. Raphael KL. Metabolic acidosis and subclinical metabolic acidosis in CKD. J Am Soc Nephrol 2018;29:376-82.

3. Wesson DE, Mathur V, Tangri N, et al. Long-term safety and efficacy of veverimer in patients with metabolic acidosis in chronic kidney disease: a multicentre, randomised, blinded, placebo-controlled, 40-week extension. Lancet 2019;394:396-406.

4. Weiner ID, Verlander JW. Recent advances in understanding renal ammonia metabolism and transport: Curr Opin Nephrol Hypertens 2016;25:436-43.

5. Kraut JA, Madias NE. Adverse effects of the metabolic acidosis of chronic kidney aisease. Adv Chronic Kidney Dis 2017;24:289-97.

6. KDIGO 2012 Clinical practice guideline for the evaluation and management of chronic kidney disease. Kidny Int Suppl 2013;3:1-150.

7. Tricida 2018 Annual Report and Proxy. Tricida. Available online: https://ir.tricida.com/financial-information/annualreports

8. Bushinsky DA. Tolerance to sodium in patients with CKD-induced metabolic acidosis: Does the accompanying anion matter? Am J Kidney Dis 2019;73:858-65.

9. Vásquez A, Domínguez C, Perdomo CF. Spontaneous gastric rupture after sodium bicarbonate consumption: A case report. Radiography 2017;23:e62-4.

10. Goraya N, Simoni J, Jo CH, et al. A comparison of treating metabolic acidosis in CKD stage 4 hypertensive kidney disease with fruits and vegetables or sodium bicarbonate. Clin J Am Soc Nephrol 2013;8:371-81. 11. Di Iorio BR, Bellasi A, Raphael KL, et al. Treatment 
Cite this article as: Brady C, Chemaly ER, Lohr JW, Parker MD. Veverimer: an advance in base therapy for metabolic acidosis. Ann Transl Med 2020;8(20):1331. doi: 10.21037/atm-20-2827

chronic kidney disease: a multicentre, randomised, double- 354 blind, controlled, phase 3 trial. Lancet 2019;393:1417-27. 355

17. de Brito-Ashurst I, Varagunam M, Raftery MJ, et al. 356 Bicarbonate supplementation slows progression of CKD $\quad 357$ and improves nutritional status. J Am Soc Nephrol JASN 358 2009;20:2075-84. 359

18. Goraya N, Simoni J, Jo CH, et al. Treatment of metabolic 360 acidosis in patients with stage 3 chronic kidney disease $\quad 361$ with fruits and vegetables or oral bicarbonate reduces $\quad 362$ urine angiotensinogen and preserves glomerular filtration $\quad 363$ rate. Kidney Int 2014;86:1031-8. 364

19. Phisitkul S, Khanna A, Simoni J, et al. Amelioration of 365 metabolic acidosis in patients with low GFR reduced $\quad 366$ kidney endothelin production and kidney injury, and better 367 preserved GFR. Kidney Int 2010;77:617-23. 368

20. Raphael KL, Murphy RA, Shlipak MG, et al. Bicarbonate 369 concentration, acid-base status, and mortality in the $\quad 370$ health, aging, and body composition study. Clin J Am Soc 371 Nephrol 2016;11:308-16. 372 